\title{
Article \\ Research on Energy-Capture Characteristics of a Direct-Drive Wave-Energy Converter Based on Parallel Mechanism
}

\author{
Tao Yao ${ }^{1,2}, * \mathbb{C}$, Yulong Wang ${ }^{1,2}{ }^{(}$, Zhihua Wang ${ }^{3}\left(\mathbb{D}\right.$, Tongxian $\mathrm{Li}^{1,2}$ and Zhipeng Tan ${ }^{1,2}$ \\ 1 School of Mechanical Engineering, Hebei University of Technology, Tianjin 300130, China; \\ 201921202003@stu.hebut.edu.cn (Y.W.); 202031205009@stu.hebut.edu.cn (T.L.); \\ 202121202069@stu.hebut.edu.cn (Z.T.) \\ 2 National Engineering Research Center for Technological Innovation Method and Tool, \\ Hebei University of Technology, Tianjin 300130, China \\ 3 School of Electrical Engineering, Hebei University of Technology, Tianjin 300130, China; \\ wangzhihua@hebut.edu.cn \\ * Correspondence: yaotao@hebut.edu.cn; Tel.: +86-13821267293
}

check for updates

Citation: Yao, T.; Wang, Y.; Wang, Z.; Li, T.; Tan, Z. Research on EnergyCapture Characteristics of a DirectDrive Wave-Energy Converter Based on Parallel Mechanism. Energies 2022, 15, 1670. https://doi.org/10.3390/ en15051670

Academic Editor: Alon Kuperman

Received: 4 January 2022

Accepted: 16 February 2022

Published: 23 February 2022

Publisher's Note: MDPI stays neutral with regard to jurisdictional claims in published maps and institutional affiliations.

Copyright: (c) 2022 by the authors. Licensee MDPI, Basel, Switzerland. This article is an open access article distributed under the terms and conditions of the Creative Commons Attribution (CC BY) license (https:// creativecommons.org/licenses/by/ $4.0 /)$.

\begin{abstract}
Aiming at the capture and conversion of multidirection wave energy, a multifreedom directdrive wave-energy converter (WEC) based on a parallel mechanism is studied. The dynamic model of WEC was conducted based on force analysis and hydrodynamic theory, and the inverse kinematic solutions of each branch chain of the mechanism were obtained following the space vector method. Furthermore, the kinetics response of the linear generator branch chain was obtained. Moreover, the influence on the capture efficiency of the device's geometric structure scale was investigated under different sea conditions. To evaluate the performance of the WEC, a linear generator model was simulated and analyzed by COMSOL Multiphysics. A laboratory prototype was manufactured. The test results indicated that the multifreedom device can achieve better power conversion performance than traditional single degree of freedom (DOF) devices. This study provides ideas for the design and development of large multi-DOF wave-energy-conversion devices.
\end{abstract}

Keywords: point absorbers; parallel mechanism; power take-off (PTO); permanent-magnet generators; dynamic response; wave-energy converter

\section{Introduction}

Effective utilization of wave energy has greatly promoted the development of renewable energy. Different kinds of wave-energy converters (WECs) have been extensively studied such as buoyancy pendulum [1], oscillating water column [2], and point absorber WECs [3]. Through the analysis of the mechanism and research status of different types of WECs, their advantages and disadvantages are shown in Table 1. Among them, point absorber WECs has the advantages of a simple structure and a high conversion rate, which is widely used in deep water far from shore and has broad development prospects [4].

Table 1. Comparison of different types of wave generator.

\begin{tabular}{ccc}
\hline Type & Advantages & Disadvantages \\
\hline Oscillating water column & $\begin{array}{c}\text { Corrosion resistance and high } \\
\text { reliability }\end{array}$ & $\begin{array}{c}\text { Low power generation } \\
\text { efficiency }\end{array}$ \\
Buoyancy pendulum & $\begin{array}{c}\text { High power generation efficiency } \\
\text { and strong scalability } \\
\text { Ptrong adaptability for marine } \\
\text { environment }\end{array}$ & $\begin{array}{c}\text { Performance is affected by } \\
\text { wave direction }\end{array}$ \\
Point absorber & \begin{tabular}{c} 
High maintenance cost \\
\hline
\end{tabular}
\end{tabular}

The direct-drive linear generator was invented in the wave power project at Uppsala University [5]. Dawoong Son et al. designed a point absorber WEC and discussed the 
coupling dynamics between linear generator structure and fluid [6]. Qiu designed the number of turns and wire diameter of the primary middle winding of linear generator in sections [7]. Selim Molla et al. optimized the winding mode of the copper coil inside the linear generator based on ANSYS/Maxwell software [8]. A new cycloidal-type WEC is explained with numerical simulation to estimate the power absorption annually [9]. A novel dual-port direct-drive linear generator is proposed in [10], which can generate electrical power even at zero vertical velocity of the buoy with the aid of a driven translator.

PTO parameter optimization and control has been a main topic of research. Tunde Aderinto et al. proposed a point absorber using the inertia (weight) of the ballast and pressure relief automatic adjustment device of seawater, which can resonate with two different wave frequencies and broaden the frequency bandwidth of wave energy [11]. C.J. Cargo et al. used an open-loop capture system to adjust PTO parameters to obtain better damping parameters [12]. In addition, some researchers have proposed a dampingcontrol method for WEC. Ye Jun Oh et al. established a dynamic model of the linear generator under high-speed conditions and proposed a PTO damping-control strategy for wave-energy conversion to achieve efficient extraction of wave energy [13].

Some nonlinear structures to match the wave conditions are proposed. Davood et al. demonstrated a wave-energy converter consisting of a nonlinear bistable system to broaden the frequency of wave-energy acquisition and improve the efficiency of wave-energy conversion [14]. Zhang et al. established a point absorber with nonlinear spring and discussed the influence of the nonlinear factors on wave-energy capture [15]. In 2014, Zhang et al. theoretically introduced the nonlinearity of the PTO system and proposed a straight-through double-spring system. Compared with a typical single-spring linear PTO, the straight-through system exhibits negative stiffness characteristics in the moving process. It leads to highly chaotic behaviors at low amplitudes and frequencies, thus increasing the power capture efficiency [16].

Most WECs can absorb wave energy only in the heaving direction. It is of great significance to design a kind of multi-DOF WEC that can convert the kinetic energy and potential energy of multidimensional waves into electric energy. Kevin Tarrant analyzed a point absorber with multi-DOF and studied the parametric coupled resonance phenomenon of the device caused by ocean incident waves. When the frequency of incident excitation waves is twice the pitch/roll resonance frequency, coupled vibration of two or more degrees of freedom occurs [17]. Chen proposed a new three-DOF WEC. Under different sea conditions (i.e., wave excitation of heave, pitch, and roll motion), the instantaneous and average output power of the device were calculated by linear time-domain simulation. The results confirmed that the WEC with multi-DOF has higher conversion efficiency [18].

This work presents a WEC based on a 3-UPU parallel mechanism. The parallel mechanism contains three identical branch chains of UPU type. Each branch chain is a prismatic pair $(\mathrm{P})$, and the mover and stator are, respectively, connected with the moving float and the fixed platform through the universal joint (U). The WEC overcomes the limitation of single-DOF energy conversion and takes full advantage of the structural characteristics of the parallel mechanism, which can extract and convert multidirection wave energy into electricity. The paper is organized as follows: firstly, the dynamic model was established in combination with the force analysis of the moving platform. Secondly, based on COMSOL Multiphasic finite element simulation software, the generator performance was discussed and the power generation performance of each branch chain of the WEC was evaluated. In accordance with the numerical model and theoretical basis, an experimental prototype is finally manufactured and installed. Experiments are conducted to measure the output electric power.

\section{Structure Design}

The direct-drive WEC system based on 3-UPU parallel mechanism is shown in Figure 1, and consists of three parts: a fixed base, a moving platform, and three linear generators located with branch chains. In order to capture the wave energy effectively, a hemispherical 
buoy was mounted to the moving platform. The buoy contacts with the ocean surface and follows the wave motion. Linear generators have the same structural parameters, acting as power take-off. The translator connected with the moving platform through a universal joint. The stator connected with the fixed base. The fixed base is stabilized in a reasonable height to ensure that the buoy is in contact with the sea level. The stator and the translator are connected via a spring.

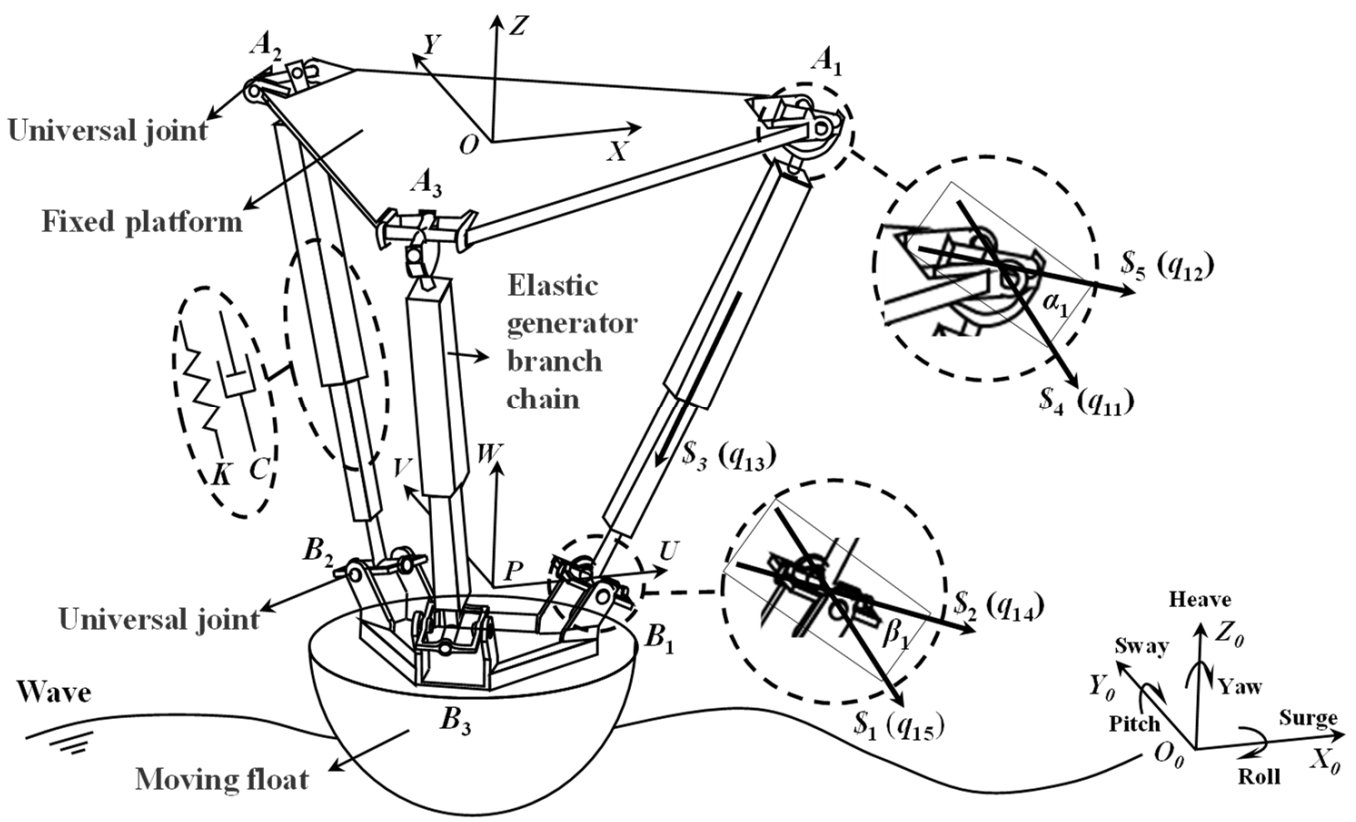

Figure 1. Schematic diagram of 3-UPU parallel mechanism.

The coordinate system used to define the system dynamics is shown in Figure 1. A global coordinate system $\mathrm{O}-\mathrm{XYZ}$ is established on the fixed base, and the $\mathrm{O}-\mathrm{XY}$ plane is parallel to the static ocean surface. A moving frame P-UVW is attached to the moving platform center, and the P-UV plane is parallel to the $\mathrm{O}-\mathrm{XY}$ plane in initial moment. A coordinate system $\mathrm{O}_{0}-\mathrm{X}_{0} \mathrm{Y}_{0} \mathrm{Z}_{0}$ is set up on the horizontal plane, which is convenient for hydrodynamic calculation and six motion modes of float are marked on it.

The DOF of the mechanism can be calculated by Chebyshev-Grubler-Kutzbach criterion:

$$
M=\gamma(n-j-1)+\sum_{r=1}^{j} f_{r}-f_{p}=3
$$

where $M$ is the DOF of the mechanism; $\gamma$ is spatial DOF; $n$ is the number of components in the mechanism; $j$ is the number of motion pairs of the mechanism; $f_{r}$ is the DOF of the motion pair $r ; f_{p}$ is all the passive degrees of freedom of the mechanism.

The screw theory proposed by Huang Zhen [19] was adopted to verify the DOF of the WEC, and a coordinate system was established for the single branch chain, as illustrated in Figure 1, the cross axes of the universal joint attached to the base were recombined with $\mathrm{X}$-axis and $\mathrm{Y}$-axis, and the $\mathrm{Z}$-axis pointed to the movement direction of the branch chain. The kinematic screw system of the branch chain was established as follows:

$$
\begin{aligned}
& \$_{1}=\left(\begin{array}{llllll}
0 & 1 & 0 ; & 0 & 0 & 0
\end{array}\right) ; \$_{2}=\left(\begin{array}{cccccc}
1 & 0 & 0 ; & 0 & 0 & 0
\end{array}\right) ; \$_{3}=\left(\begin{array}{llllll}
0 & 0 & 0 ; & 0 & 0 & 1
\end{array}\right) \\
& \$_{4}=\left(\begin{array}{llllll}
1 & 0 & 0 ; & 0 & a_{1} & 0
\end{array}\right) ; \$_{5}=\left(\begin{array}{cccccc}
0 & 1 & 0 ; & a_{2} & 0 & 0
\end{array}\right)
\end{aligned}
$$

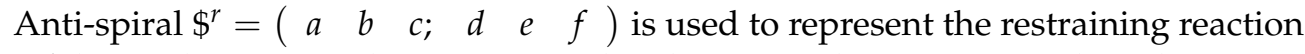
force of the mechanism. Each moving spiral and anti-spiral are a reciprocal product:

$$
\$_{j} \circ \$^{r}=0 j=1,2,3,4,5
$$


Thus, the unique constraint helix of the branch chain is obtained:

$$
\$^{r}=\left(\begin{array}{llllll}
0 & 0 & 0 ; & 0 & 0 & 1
\end{array}\right)
$$

Each branch chain generates a constraint couple perpendicular to the plane of the crosshead of the respective universal joint, and the couples are not parallel to each other. Together, three constraint couples limit the three degrees of freedom of rotation of the float. Consequently, the mechanism satisfies the balance between the sum of the rotating moments acting on the float and the three constraint couples at any time. The moving platform always has three-dimensional translational degrees of freedom.

To ensure that the 3-UPU parallel mechanism adopted has three-dimensional translational degrees of freedom, the installation parameters of the linear generator branch chain and the universal joints that connects the branch chain with the fixed base and moving platform are restricted as follows:

(1) $q_{i 1}$ and $q_{i 5}$ are, respectively, related to the outer circle of the corresponding platform;

(2) $q_{i 2} / / q_{i 4}$;

(3) $\alpha_{i} / / \beta_{i}$.

Among them, $q_{i 1}$ and $q_{i 5}$ are, respectively, rotating auxiliary axes connected with the moving platform and fixed base in the branch chain $i ; q_{i 2}$ and $q_{i 4}$ are rotating auxiliary axes of the universal joint at both ends of the $i$-th branch chain $(i=1,2,3)$; $\alpha \mathrm{i}$ and $\beta \mathrm{i}$ represent the plane where the crosshead of the respective universal joint is located in the fixed base and the moving float, respectively.

\section{Theoretical Analysis}

\subsection{Model Description}

As shown in Figure 2, three joints on the fixed base form an equilateral triangle $A_{1} A_{2} A_{3}$ with a length $a$. In the global coordinate system $O-X Y Z$, the coordinates of the origin $O$ in the fixed coordinate system are $(0,0,0)$. The coordinates of each hinge point can be expressed as:

$$
A_{1}=\left[\begin{array}{lll}
\frac{a}{\sqrt{3}} & 0 & 0
\end{array}\right], A_{2}=\left[\begin{array}{lll}
\frac{-a}{2 \sqrt{3}} & \frac{a}{2} & 0
\end{array}\right], A_{3}=\left[\begin{array}{ccc}
\frac{-a}{2 \sqrt{3}} & \frac{-a}{2} & 0
\end{array}\right]
$$

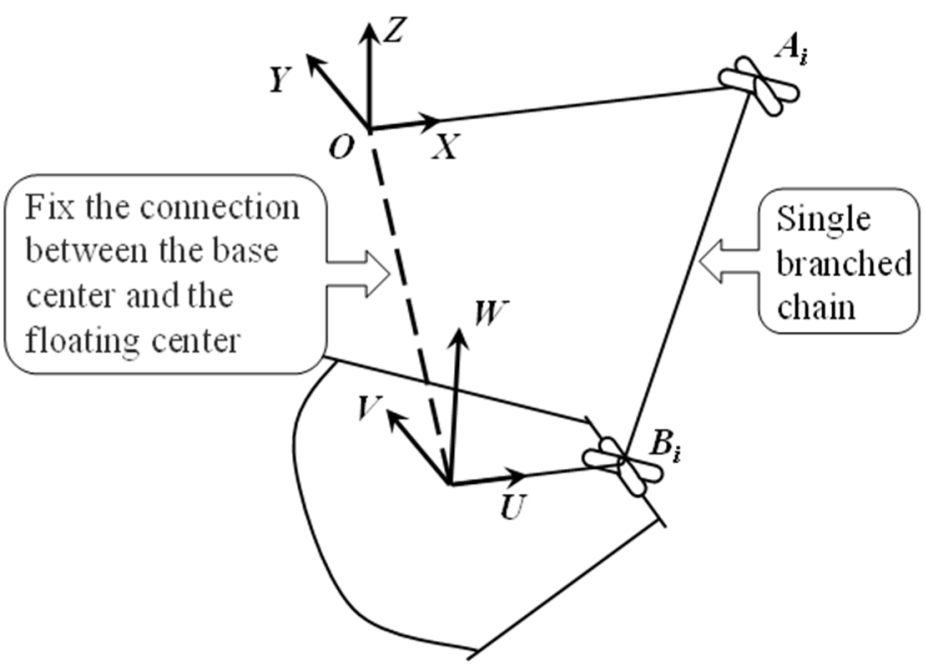

Figure 2. The coordinate of a single branched chain.

Under the moving coordinate system $P-U V W$, the three-hinged joints of kinematic pairs on a moving platform form an equilateral triangle $B_{1} B_{2} B_{3}$ with a length $b$. The coordinates of each hinge point can be expressed as:

$$
B_{1}=\left[\begin{array}{lll}
\frac{b}{\sqrt{3}} & 0 & 0
\end{array}\right], B_{2}=\left[\begin{array}{lll}
\frac{-b}{2 \sqrt{3}} & \frac{b}{2} & 0
\end{array}\right], B_{3}=\left[\begin{array}{lll}
\frac{-b}{2 \sqrt{3}} & \frac{-b}{2} & 0
\end{array}\right]
$$


The vector change of each branch can be uniquely expressed by the closed-loop equation as:

$$
\mathbf{l}_{i}=\mathbf{A}_{i} \mathbf{B}_{i}=-\mathbf{O A} \mathbf{A}_{i}+\mathbf{O P}+\mathbf{P} \mathbf{B}_{i}
$$

\subsection{Dynamic Analysis}

According to Newton's second law, the motion equation of the moving platform can be expressed as:

$$
\mathbf{M} \xi^{\prime \prime}+\mathbf{F}_{C}+\mathbf{F}_{K}=\mathbf{F}_{W}-m g
$$

where $\xi=\left[\begin{array}{lll}x & y & z\end{array}\right]^{T}$ is the motion vector of the buoy and $\xi^{\prime \prime}$ is the acceleration; $\mathbf{M} \in \mathbf{R}^{3 \times 3}$ is the mass matrix of the moving float; $\mathbf{F}_{C}$ is the damping force; $\mathbf{F}_{K}$ is spring force; $\mathbf{F}_{W}$ is the force of the wave on the moving float, $m$ is the mass of the float; $g$ is the acceleration of gravity.

The force is expressed as:

$$
\mathbf{F}_{w}=\mathbf{F}_{b}+\mathbf{F}_{r}+\mathbf{F}_{F K}
$$

where $\mathbf{F}_{b}$ is hydrostatic buoyancy; $\mathbf{F}_{r}$ is the wave radiation force; $\mathbf{F}_{F K}$ is the wave excitation and additional mass effect calculated using the Froude-Krylov hypothesis.

\subsubsection{Spring Force $\mathbf{F}_{K}$}

The translator and stator are connected by springs with the same stiffness coefficient. Each elastic moving branch chain will affect the movement of the moving float through the spring force, and the force is described as follows:

$$
\mathbf{F}_{\mathbf{k} i}=\frac{\mathbf{1}_{i}}{\left|\mathbf{1}_{i}\right|}\left(\left|\mathbf{1}_{i}\right|-l_{0}\right) \cdot K
$$

where $l_{0}$ is the original length of the nonstretched linear power generation branch chain; $\left|\mathbf{1}_{i}\right|$ is the length of the moving branch chain; $K$ is the spring stiffness coefficient.

The length of each moving branch chain in the following form can be uniquely determined by Equation (5):

$$
\left\{\begin{array}{c}
\left|\mathbf{1}_{\mathbf{1}}\right|=\sqrt{\left(\frac{b}{\sqrt{3}}-\frac{a}{\sqrt{3}}+x\right)^{2}+y^{2}+z^{2}} \\
\left|\mathbf{1}_{\mathbf{2}}\right|=\sqrt{\left(\frac{a}{2 \sqrt{3}}-\frac{b}{2 \sqrt{3}}+x\right)^{2}+\left(\frac{b}{2}-\frac{a}{2}+y\right)^{2}+z^{2}} \\
\left|\mathbf{1}_{3}\right|=\sqrt{\left(\frac{a}{2 \sqrt{3}}-\frac{b}{2 \sqrt{3}}+x\right)^{2}+\left(\frac{a}{2}-\frac{b}{2}+y\right)^{2}+z^{2}}
\end{array}\right.
$$

where $x, y$ and $z$ indicate the instantaneous velocity in the time domain.

\subsubsection{Electromagnetic Damping Force $\mathbf{F}_{C}$}

When the translator and stator move relatively, the kinetic energy of the generator was converted into electric energy, which satisfies the law of electromagnetic induction. Considering the damping force is linear, its function is expressed as:

$$
\mathbf{F}_{C i}=C \cdot \mathbf{l}_{i}{ }^{\prime}
$$

where $C$ is the electromagnetic damping coefficient.

The motion speed of translator can be obtained by compound derivation of the change in the rod length based on the inverse kinematics described in Equation (11):

$$
\mathbf{1}_{i}{ }^{\prime}=\left[\begin{array}{l}
\mathbf{l}_{\mathbf{1}}{ }^{\prime} \\
\mathbf{1}_{\mathbf{2}}{ }^{\prime} \\
\mathbf{1}_{\mathbf{3}}{ }^{\prime}
\end{array}\right]=\left[\begin{array}{lll}
\left|\mathbf{l}_{\mathbf{1}}\right| & & \\
& \left|\mathbf{l}_{\mathbf{2}}\right| & \\
& & \left|\mathbf{1}_{\mathbf{3}}\right|
\end{array}\right]^{-1}\left[\begin{array}{ccc}
\frac{b}{\sqrt{3}}-\frac{a}{\sqrt{3}}+x & y & z \\
\frac{a}{2 \sqrt{3}}-\frac{b}{2 \sqrt{3}}+x & \frac{b}{2}-\frac{a}{2}+y & z \\
\frac{a}{2 \sqrt{3}}-\frac{b}{2 \sqrt{3}}+x & \frac{a}{2}-\frac{b}{2}+y & z
\end{array}\right]\left[\begin{array}{l}
x^{\prime} \\
y^{\prime} \\
z^{\prime}
\end{array}\right]
$$


where $x^{\prime}, y^{\prime}$, and $z^{\prime}$ indicate the instantaneous velocity in the time domain.

\subsubsection{Hydrostatic Buoyancy}

The surface of the hemispherical buoy is always in contact with the ocean surface. The hydrostatic buoyancy is expressed as:

$$
\mathbf{F}_{b}=\rho g V_{b}=\rho g \int_{R-z_{0}}^{R} \pi u^{2} d w=\frac{1}{3} \rho g \pi\left|z_{0}\right|^{2}\left(3 R-\left|z_{0}\right|\right)
$$

where $\rho$ is seawater density; $g$ is the gravitational acceleration; $V_{b}$ is the submerged volume of the hemispherical moving float in water; $R$ is the float radius; $\left|z_{0}\right|$ is the distance from the bottom of the float to the sea level.

\subsubsection{Wave Radiation Force}

The fluid reaction caused by the swinging motion of the buoy in still water is defined as the radiation force. Usually, the radiation force is analyzed without considering the incident wave, which can be expressed by convolution integral [20]:

$$
\mathbf{F}_{r}=\int_{0}^{t} \mathbf{k}_{r}(t-\tau) \xi^{\prime \prime}(\tau) d \tau
$$

where $\mathbf{k}_{r}(t)$ represents the effect of fluid in radiation and can be written:

$$
\mathbf{k}_{r}(t)=\frac{2}{\pi} \int_{0}^{\infty} \mathbf{B}(\omega) \cos (\omega t) d \omega
$$

where $\mathbf{B}(\omega)$ is the radiation damping coefficient of the buoy during movement.

A frequency-domain hydrodynamic software package with multibody functionality (such as Wave Analysis MIT) can be used to obtain the damping coefficients $\mathbf{B}(\omega)$ ). Therefore, following the approach proposed by Ogilvie [21], the frequency-dependent hydrodynamic damping coefficients can be transformed into frequency-independent radiation impulse response functions in the time domain.

\subsubsection{Wave Excitation Calculated by Froude-Krylov Method}

When the ratio of wave height $H$ to buoy height $l$ satisfies $H / l<1$, the Froude-Krylov assumption method can be used to calculate the wave excitation force. The multiplication of the Froude-Krylov force by coefficient $c$ reflects the additional mass effect and the correction of the wave excitation force $[17,22]$. The expression is written:

$$
\begin{gathered}
\mathbf{F}_{F K}=c \iint_{S}-\rho \mathbf{n} d S \\
\left\{\begin{array}{l}
\mathbf{F}_{F K-x}=c_{H} \iint_{S} p_{x} d S \\
\mathbf{F}_{F K-z}=c_{V} \iint_{S} p_{z} d S
\end{array},\right.
\end{gathered}
$$

where $c_{H}$ is the horizontal diffraction coefficient, $c_{V}$ is the vertical diffraction coefficient, $p_{x}$ is the wave pressure component of the undisturbed linear incident wave in the direction $x$ above the surface of the submersible, $p_{y}$ is the wave pressure component of the undisturbed linear incident wave upward above the surface $y$ of the submersible, $\mathbf{n}$ is the external normal unit vector of a point on the surface of the structure, $S$ is the total surface area of the submersible, $d S$ is the surface area of the submersible primitive.

According to the linearized Bernoulli equation, the expression of hydrodynamic pressure of incident wave is as follows:

$$
P=-\rho \frac{\partial \Phi}{\partial t}
$$


where $\Phi$ is the potential function of undisturbed wave velocity, and its expression is:

$$
\Phi=\frac{g H}{2 \omega} \frac{\cosh k\left(z_{0}+d\right)}{\cosh k d} \sin \left(k x_{0}-\omega t\right)
$$

where $d$ is the water depth, $H$ is the sea water density, $k$ is the wave height and can be expressed as $k=2 \pi / \lambda, z_{0}$ is the coordinate of the center of the submersible in the sea-level coordinate system, and $\omega$ is the angular frequency of the wave.

It should be noted that the hydrodynamic pressure decreases with the increase in the distance between the mass center of the submerged part of the floating body and the static horizontal plane. To ensure the effectiveness of the numerical model, it is assumed that when $z_{0}>0$, the hydrodynamic pressure is equal to the hydrostatic pressure, and the pressure can be expressed as $[23,24]$ :

$$
P=\left\{\begin{array}{c}
\frac{\rho g H}{2} \frac{\cosh k\left(z_{0}+d\right)}{\cosh k d} \cos \left(k x_{0}-\omega t\right) \quad z_{0} \leq 0 \\
\rho g\left(\eta-z_{0}\right) \quad z_{0}>0
\end{array}\right.
$$

where $\eta$ is the wave surface equation of linear wave, and the expression is $\eta=\frac{H}{2} \cos (k x-\omega t)$.

In combination with the draft of the moving float, Equation (16) can be written as:

$$
\begin{aligned}
& F_{F K-x}=c_{H} \frac{\pi \rho g H k\left|z_{0}\right|^{2}}{6 \cosh (k d)}\left(3 R-z_{0}\right)\left[\cosh \left(k\left(d-z_{0}\right)\right)+C_{1} \sinh \left(k\left(d-z_{0}\right)\right)\right] \sin (\omega t) \\
& F_{F K-z}=c_{V} \frac{\pi \rho g k H\left|z_{0}\right|^{2}}{6 \cosh (k d)}\left(3 R-z_{0}\right)\left[-\sinh \left(k\left(d-z_{0}\right)\right)+C_{2} \cosh \left(k\left(d-z_{0}\right)\right)\right] \cos \omega t
\end{aligned}
$$

where $C_{1}$ and $C_{2}$ are wave excitation coefficients.

\subsection{Numerical Model Solution}

The dynamic model of Equation (6) can be rewritten as:

$$
\begin{aligned}
& {\left[\begin{array}{lll}
m & & \\
& m & \\
& & m
\end{array}\right]\left[\begin{array}{l}
x^{\prime \prime} \\
y^{\prime \prime} \\
z^{\prime \prime}
\end{array}\right]+C\left(\left[\begin{array}{lll}
x^{\prime} & x^{\prime} & x^{\prime} \\
y^{\prime} & y^{\prime} & y^{\prime} \\
z^{\prime} & z^{\prime} & z^{\prime}
\end{array}\right]\left[\begin{array}{l}
\frac{L_{1}}{\left|1_{1}\right|} \\
\frac{L_{2}}{\left|\mathbf{1}_{2}\right|} \\
\frac{L_{3}}{\left|\mathbf{1}_{3}\right|}
\end{array}\right]+\left[\begin{array}{ccc}
x-\Delta & x+\frac{\Delta}{2} & x+\frac{\Delta}{2} \\
y & y-\frac{\sqrt{3}}{2} \Delta & y+\frac{\sqrt{3}}{2} \Delta \\
z & z & z
\end{array}\right]\left[\begin{array}{l}
-\frac{\mathbf{l}_{1}{ }^{\prime}}{\left|\mathbf{1}_{1}\right|} \\
-\frac{\mathbf{1}_{2}^{\prime}}{\left|\mathbf{1}_{2}\right|} \\
-\frac{\mathbf{1}_{3}^{\prime}}{\left|\mathbf{1}_{3}\right|}
\end{array}\right]\right)} \\
& +K\left[\begin{array}{ccc}
x-\Delta & x+\frac{\Delta}{2} & x+\frac{\Delta}{2} \\
y & y-\frac{\sqrt{3}}{2} \Delta & y+\frac{\sqrt{3}}{2} \Delta \\
z & z & z
\end{array}\right]\left[\begin{array}{c}
-\frac{L_{1}}{\left|\mathbf{l}_{1}\right|} \\
-\frac{L_{2}}{\left|\mathbf{I}_{2}\right|} \\
-\frac{L_{3}}{\left|\mathbf{l}_{3}\right|}
\end{array}\right] \\
& =\mathbf{F}_{b}+\mathbf{F}_{r}+\mathbf{F}_{F K}-m g
\end{aligned}
$$

where $x^{\prime \prime}, y^{\prime \prime}$, and $z^{\prime \prime}$ indicate the instantaneous acceleration in the time domain, $\Delta=(a-b) / \sqrt{3}, L_{i}=l_{0}-\left|\mathbf{1}_{i}\right|, i=1,2,3$.

The impact of structural geometric parameters on the power generation efficiency was investigated in this paper. It can be seen from Equation (22) that the moving buoy and platform drives the translator to move under wave excitation. Assume that the mechanism is in the static equilibrium position initially, the hemispherical buoy is partially submerged in the seawater, and the spring is unreformed. The structural parameters of are shown in Table 2. The fourth-order Runge-Kutta method was used to solve the dynamic model.

The wave energy includes the potential energy of fluctuation and the kinetic energy of ocean current flow. According to the linear theory of ocean surface wave, the energy density per unit wavelength in deep water can be calculated as [8]:

$$
P_{\text {wave }}=\frac{\rho g^{2}}{64 \pi} H^{2} T
$$


where $\rho$ is the sea water density; $g$ is the gravitational acceleration; $H$ is the effective height of the wave, and $T$ is the wave period.

Table 2. The structural parameters of the device.

\begin{tabular}{cc}
\hline Item & Size \\
\hline Initial length of elastic power generation branch chain $l_{0}$ & $0.6 \mathrm{~m}$ \\
Maximum stroke of elastic power generation branch chain & $0.2 \mathrm{~m}$ \\
Hemispherical float radius $R$ & $0.3 \mathrm{~m}$ \\
Hemispherical float mass $m$ & $17.76 \mathrm{~kg}$ \\
Hemispherical float draft & $0.15 \mathrm{~m}$ \\
Spring stiffness $K$ & $300 \mathrm{~kg} / \mathrm{m}$ \\
Damping $C$ & $171.4 \mathrm{~N} \cdot \mathrm{s} / \mathrm{m}$ \\
\hline
\end{tabular}

The relative motion of the translator and stator in the linear generator converts the mechanical energy into electrical energy. The average wave energy obtained by the conversion system can be expressed as:

$$
P_{\text {generator }}=\sum_{i=1}^{3} \frac{1}{T} \int_{0}^{T} C \cdot l_{i}^{\prime 2} d t
$$

The damping coefficient $C$ can be obtained according to Figure 3 . First, the damping value of the similar-sized generators working under similar conditions is substituted into the mathematical model to calculate the speed of each power generation branch. Then, the calculated speed is the initial condition of the motion to calculate the finite element model. Next, the finite element model is compared with the mathematical model for the effective value of the voltage over a period. If the values are the same, the approximate value of the damping coefficient is reasonable; otherwise, the approximated value needs to be reselected and the calculation is repeated.

Compared with the wave power per unit area, the wave-energy conversion efficiency of the power generation system can be expressed as:

$$
\eta=\frac{P_{\text {generator }}}{P_{\text {wave }}}
$$

Which is compared with the full-size direct-drive point absorber model established by Lysekil Wave Energy Research Field, Sweden [25]. Thus, only the influence of the change in geometric size and DOF of the parallel mechanism on the wave-energy conversion efficiency is analyzed.

As shown Figure 4, under the same wave height, the efficiency of the multi-DOF WEC is higher than that of single-DOF devices, and the difference in maximum conversion efficiency can reach $11.79 \%$. It is confirmed that by increasing the freedom of the surge, wave fluctuation potential energy and flow kinetic energy can be absorbed at the same time to increase the wave-energy conversion efficiency. With the increase in the geometric size of the structure, higher wave-energy conversion efficiency can be achieved at a lower wave frequency for different motion modes. Additionally, this phenomenon is more obvious in multi-DOF devices. When the wave height $H$ changes between $0.1 \sim 0.2 \mathrm{~m}$, with the increase in wave height, the buoy may be completely submerged in the water, thus reducing the vibration speed of the power generation branch chain. Meanwhile, the total wave energy in a single cycle increases and the maximum wave-energy conversion efficiency decreases with the increase in wave height. Therefore, under the wave height of $H=0.1 \mathrm{~m}$, the wave period of $T=3 \mathrm{~s}$, and the structure size of $\Delta=0.4$, the wave-energy conversion efficiency of the multi-DOF wave-energy conversion system reaches $39.91 \%$. 


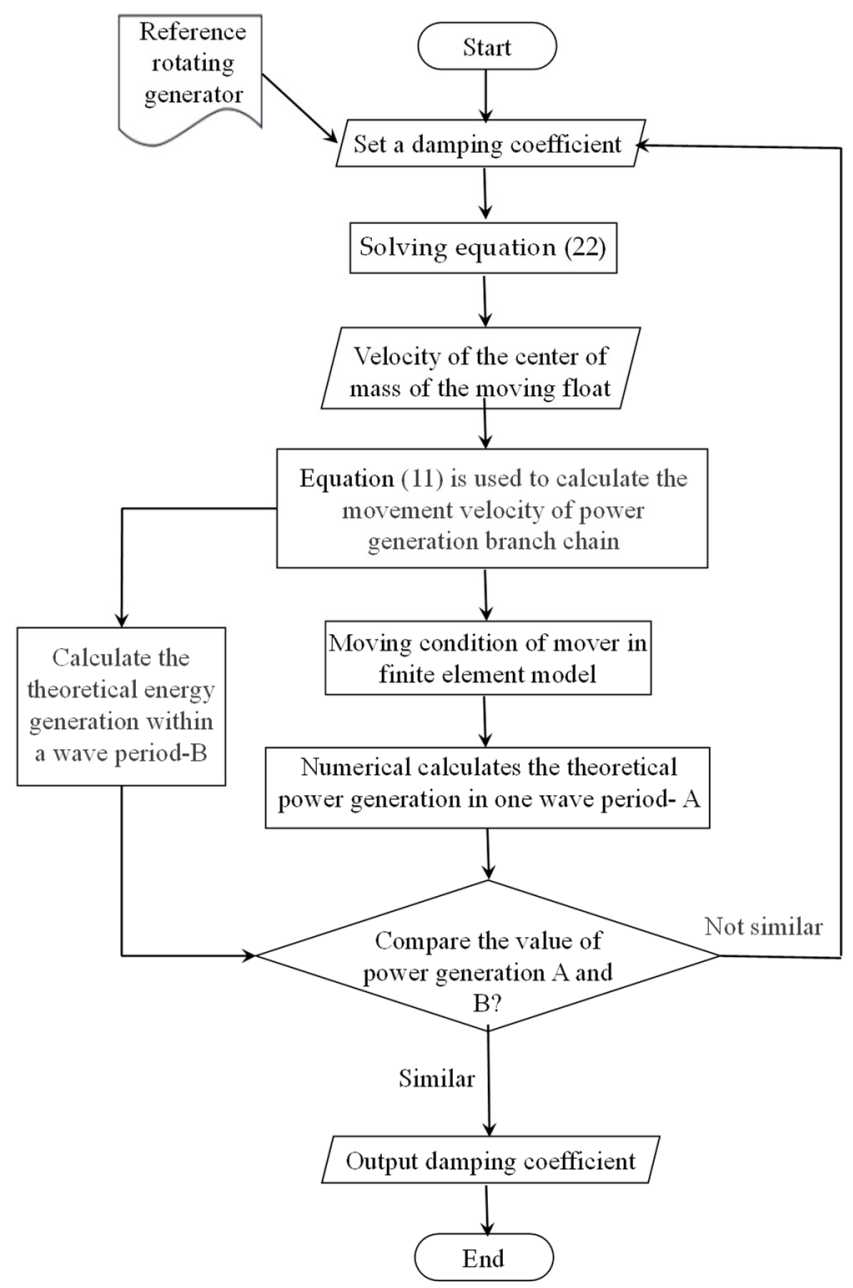

Figure 3. Proposed algorithm for damping coefficient $C$.

(a)

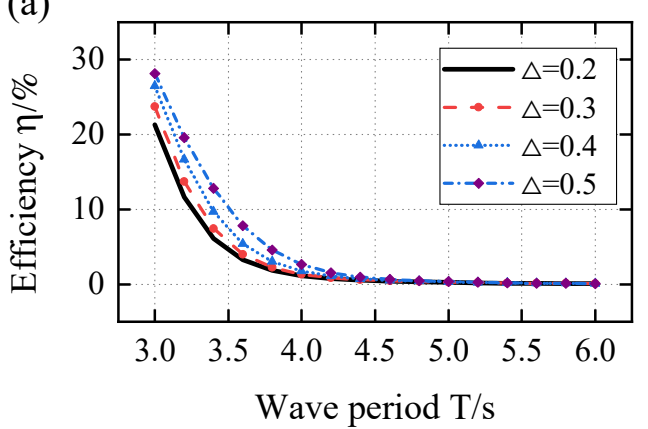

(b)

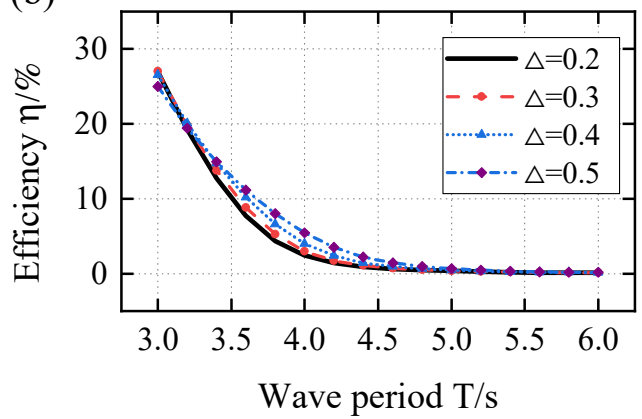

(d)

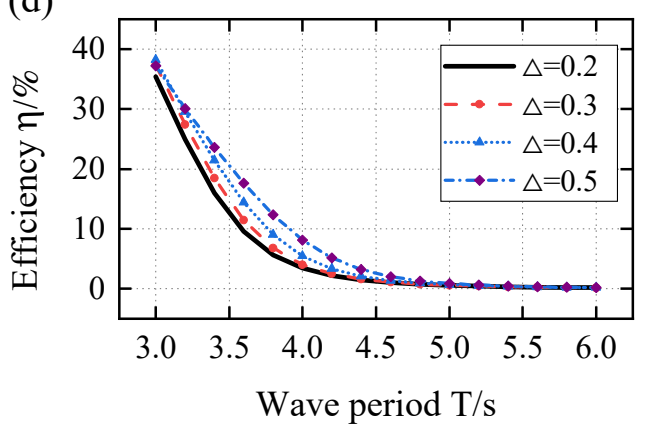

(e)

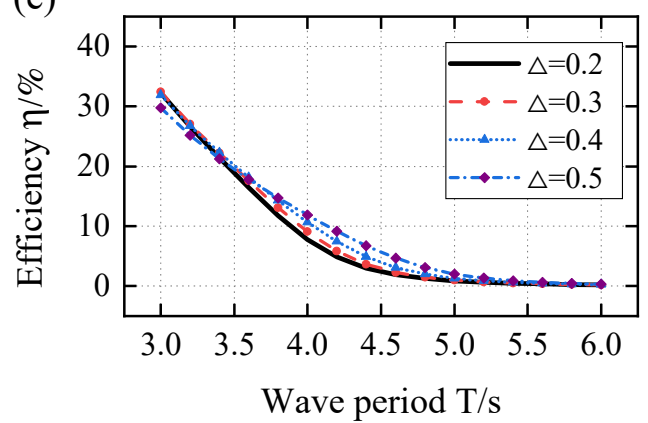

Figure 4. Cont. 
(c)

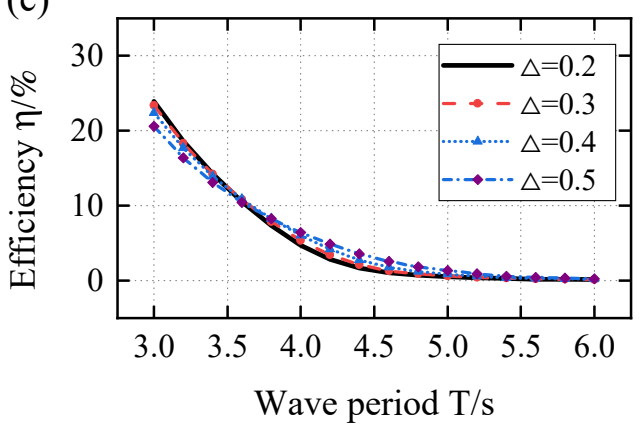

(f)

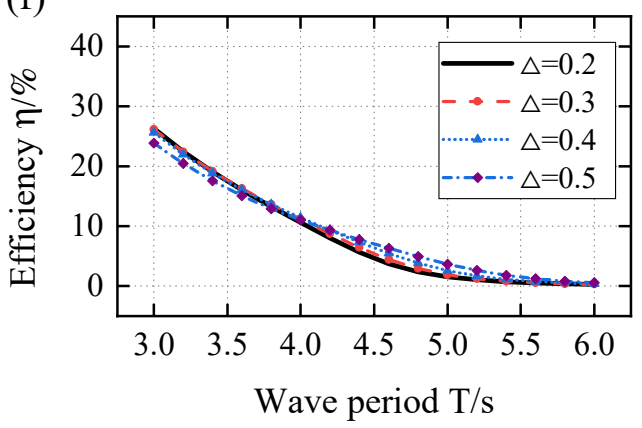

Figure 4. Comparison of the wave-energy conversion efficient with wave period from $3 \mathrm{~s}$ to $6 \mathrm{~s}$ for different structure parameter of $\Delta=0.2,0.3,0.4$, and 0.5 , and different wave height of $\mathrm{H}=0.1 \mathrm{~m}$ (a), $0.15 \mathrm{~m}(\mathbf{b})$, and $0.2 \mathrm{~m}$ (c), respectively, in single-DOF devices. Comparison of the wave-energy conversion efficient with wave period from $3 \mathrm{~s}$ to $6 \mathrm{~s}$ for different structure parameter of $\Delta=0.2,0.3$, 0.4 , and 0.5 , and different wave height of $\mathrm{H}=0.1 \mathrm{~m}(\mathbf{d}), 0.15 \mathrm{~m}(\mathbf{e})$, and $0.2 \mathrm{~m}(\mathbf{f})$, respectively, in multi-DOF devices.

\section{Simulation Analysis}

\subsection{Finite Element Model}

Based on the AC/DC module in COMSOL Multiphysics 5.6, a two-dimensional axisymmetric cylindrical linear generator model is established. The geometry and structural dimensions are shown in Table 3 and Figure 5. As can be seen from Figure 6, the motion speed of the translator is obtained from the dynamic analysis results of Equation (22) in the Section 3.3.

$$
\begin{gathered}
l_{i}^{\prime}=a_{i 0}+a_{i 1} \cos (\omega t)+b_{i 1} \sin (\omega t)+a_{i 2} \cos (2 \omega t)+b_{i 2} \sin (2 \omega t) \\
+a_{i 3} \cos (3 \omega t)+b_{i 3} \sin (3 \omega t)+a_{i 4} \cos (4 \omega t)+b_{i 4} \sin (4 \omega t) \\
l_{i}^{\prime} \rightarrow\left[\begin{array}{lllllllll}
a_{i 0} & a_{i 1} & b_{i 1} & a_{i 2} & b_{i 2} & a_{i 3} & b_{i 3} & a_{i 4} & b_{i 4}
\end{array}\right]
\end{gathered}
$$

$l_{1}^{\prime} \rightarrow\left[\begin{array}{lllllllll}0 & 0.16 & 0.1037 & -0.1282 & 0.04549 & 0.01878 & -0.05632 & 0.008989 & 0.01989\end{array}\right]$

$l_{2}^{\prime} \rightarrow\left[\begin{array}{lllllllll}0 & 0.1757 & 0.05278 & -0.128 & 0.09164 & 0.02568 & -0.07918 & -0.0009185 & 0.02966\end{array}\right]$

$l_{3}{ }^{\prime} \rightarrow\left[\begin{array}{lllllllll}0 & 0.1757 & 0.05278 & -0.128 & 0.09164 & 0.02568 & -0.07918 & -0.0009185 & 0.02966\end{array}\right]$

Table 3. Main structural parameters of the linear generator FEM model.

\begin{tabular}{cccc}
\hline & Description & Value $/ \mathbf{m m}$ & Exp \\
\hline \multirow{3}{*}{ Mover } & Permanent magnet (inner diameter $\times$ & $10 \times 20 \times 20$ & MID $\times$ MOD $\times$ MH \\
& external diameter $\times$ height) & 10 & ID \\
& Core diameter & 80 & ML \\
\hline \multirow{4}{*}{ Ptator } & Yoke (inner diameter $\times$ external & $22 \times 50 \times 146$ & YID $\times$ YOD $\times$ YH \\
& diameter $\times$ height) & 20 & TB \\
& Alveolar width & 11 & TH \\
& Alveolar height & 40 & TL \\
& Alveolar distance & 4 & $\mathrm{TN}$ \\
& Number of slots & 0.3 & $\mathrm{D}$ \\
\hline & Copper conductor diameter & 1 & $\mathrm{G}$ \\
\hline
\end{tabular}



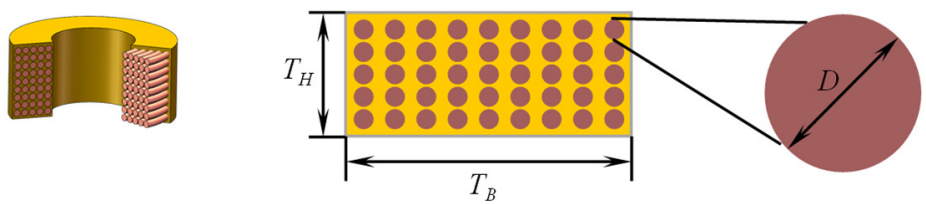

(a)
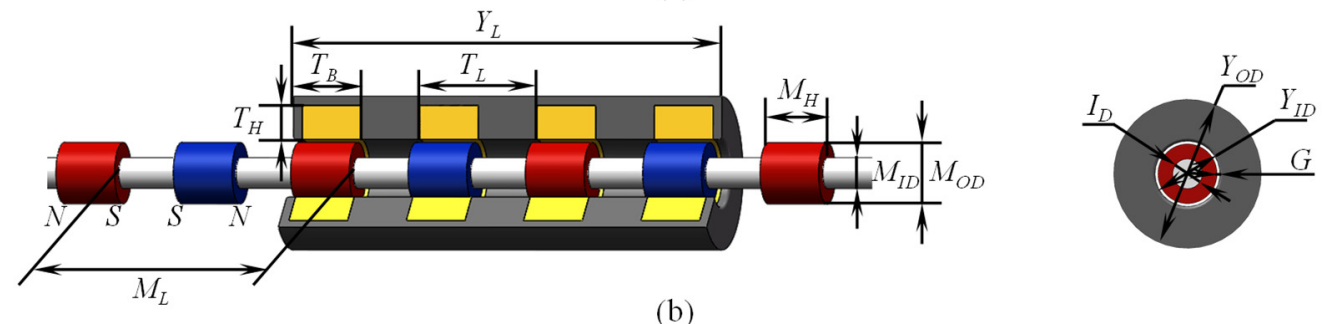

(b)

Figure 5. Main structural dimension parameters of the linear generator (a) Coil winding; (b) Linear generators.
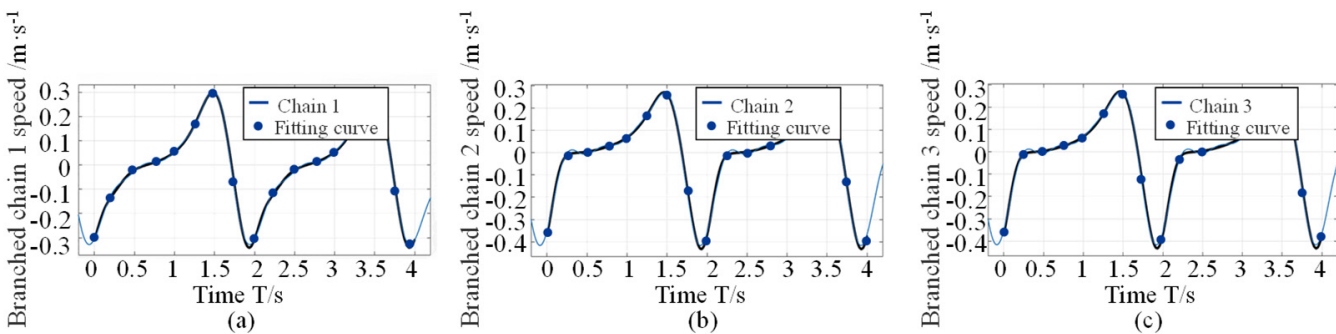

Figure 6. Fourier fitting curves of the branch chain velocity (a) The velocity of branch 1; (b) The velocity of branch 2; (c) The velocity of branch 3.

The stator yoke is made of magnetic conductive material with " $\mathrm{E}$ " cross section.

Copper coils with good conductivity are wound in the cogging of the stator yoke. To make the induced current in the simulation model transmit only in the coil, the coil domain is established in the air domain, and the conductivity of the air domain is set to zero (to ensure the convergence of calculation, the conductivity can be set to 1), i.e., the simulation coil is wrapped by an insulating layer. The mover part is set as the moving grid normal domain, and the grid velocity is shown in Equations (26)-(30). The whole magnetic field is discretized into linear elements to reduce the operation size. A direct solver with good numerical stability and robustness is adopted to calculate the electromagnetic model, and the Jacobian matrix is updated in each iterative calculation to increase the convergence and accuracy of the calculation.

Faraday's law of electromagnetic induction states that the induced electromotive force (EMF) in a closed loop is proportional to the change rate of magnetic flux across the loop over time. It is expressed by integrals as [26]:

$$
\oint_{\tau} \vec{E} \cdot d \vec{l}=-\iint_{\Omega} \frac{\partial \vec{B}}{\partial t} \cdot d \vec{S}
$$

where $\tau$ is the boundary of the surface.

The differential equation to solve the electromagnetic problems in finite element software can be obtained as follows:

$$
\nabla \times \vec{E}=-\frac{\partial B}{\partial t}
$$

For a closed loop consisting of N-ring insulated conductors, the EMF generated is expressed as: 


$$
E^{0}=-N \frac{d \phi}{d t}
$$

where $E^{0}$ represents no-load electromotive force, and $d \phi / d t$ represents the rate of change in magnetic flux. The load voltage $U_{i}$ at both ends of the linear generator can be calculated as:

$$
U_{i}=E_{i}^{0}+I_{i} r i=1,2,3
$$

where $I_{i}$ is the current; $r$ is the internal resistance of the motor, and the subscript $i$ represents the generation branch chain $i$.

The electromagnetic damping force of the generator does work to convert mechanical energy into electrical energy. Compared with the wave power in the unit area, the waveenergy conversion efficiency of the linear generator can be expressed as:

$$
\eta=\frac{\sum_{i=1}^{3} U_{i} I_{i}}{P_{\text {wave }}} i=1,2,3
$$

\subsection{Simulation Results}

The setting of the corresponding material attributes in the finite element model is listed in Table 4.

Table 4. Material attribute setting of the finite element model.

\begin{tabular}{cc}
\hline Name & Numerical Value \\
\hline Yoke conductivity & $9.93 \times 10^{6} / \mathrm{m} \Omega$ \\
Yoke dielectric constant & 14.2 \\
Permanent magnet material & $\mathrm{NdFeB}(\mathrm{N} 45)$ \\
Residual flux strength of permanent magnet (BR) & $13.6 / \mathrm{KGs}$ \\
Permanent magnet magnetic induction coercivity (HCB) & $12 / \mathrm{KOe}$ \\
Turn Ratio & 500 \\
Total resistance of coil winding & $17.46 \Omega$ \\
\hline
\end{tabular}

As shown in Figure 7, the model includes a moving domain (permanent magnet and iron core), a fixed domain (yoke and copper coil winding), and an air domain. There is an air gap between the target surface and the source surface, and the outermost side of the yoke is a magnetically insulated area. On the surface of the translator and the stator, a continuous boundary pair is created to ensure the magnetic potential and flux on both sides of the surface are continuous. It should be noted that the mesh on the target surface is denser than that on the source surface. Considering the influence of speed on the electromagnetic field in space, a moving grid is needed, and the mover domain is set as the moving area. The motion speed is obtained from the third part of the dynamic solution result. The steady-state solution is achieved under the default relative tolerance of 0.001 . After the initial value is obtained, the direct solver is used to directly inverse the algebraic equation and the transient time domain analysis is performed to improve the stability and robustness of the numerical calculation. The magnetic field is discretized into linear elements to reduce the operation size. The total solution time is set to $60 \mathrm{~s}$ and the solution step size is set to $0.01 \mathrm{~s}$. The numerical model is solved on the ThinkStation K10, a computer equipped with Intel i9-10900 processor.

The finite-element simulation results of a single unidirectional power generation branch chain are discussed here. The results of the other two branch chains are similar. During the movement of the generator mover, the magnetic induction lines in the magnetic field form a closed loop between the yoke and the magnetic core. The coils in the yoke are wound to cut the magnetic induction wire for power generation. The four winding coils are connected in series, and they are externally connected with the rectifier and filter circuit in parallel for power utilization or storage. The simulation results of the magnetic 
induction intensity and magnetic vector potential are shown in Figure 8, and the voltage waveform without rectification is shown in Figure 9.

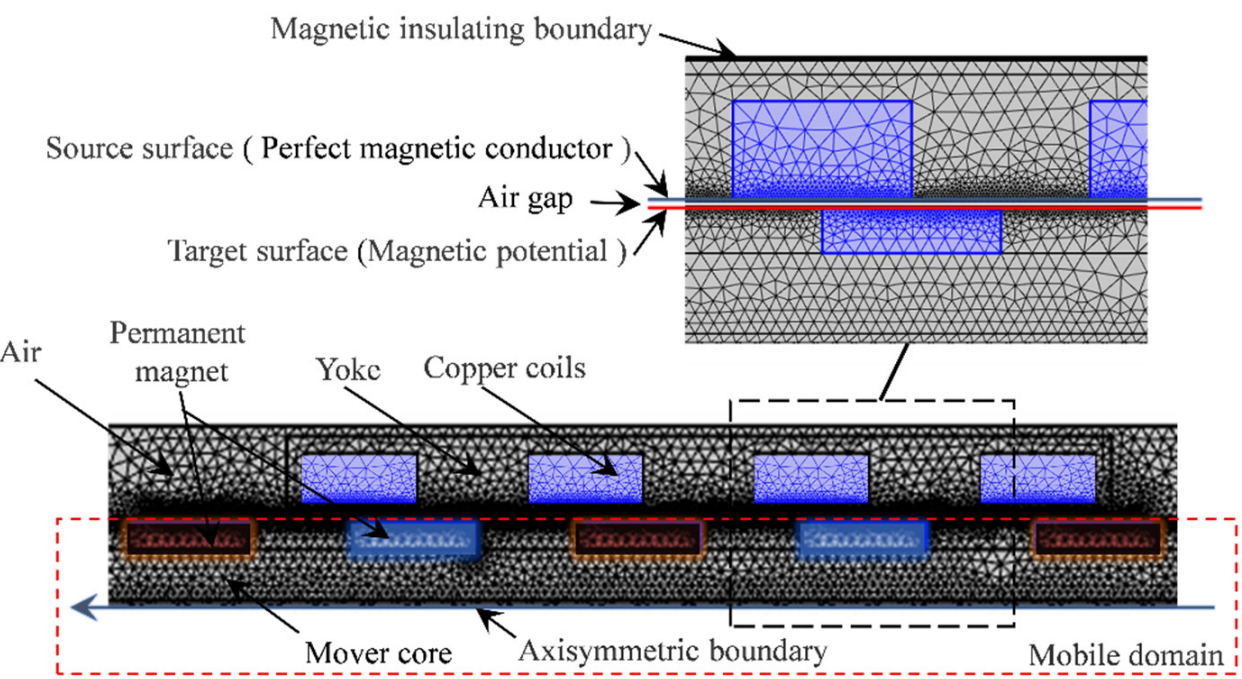

Figure 7. FEM model mesh and boundary conditions.

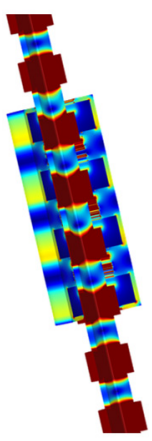

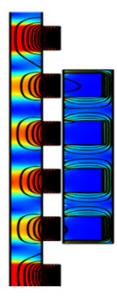

$0 \mathrm{~s}$

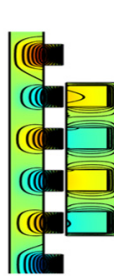

Os

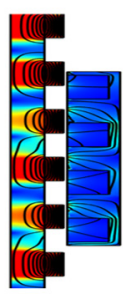

$1 \mathrm{~s}$

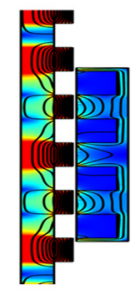

$2 \mathrm{~s}$
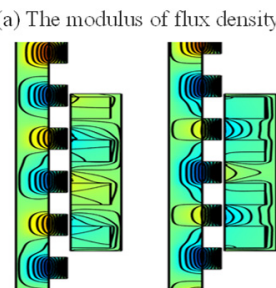

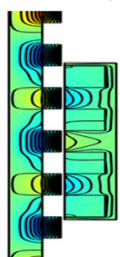

$2 \mathrm{~s}$
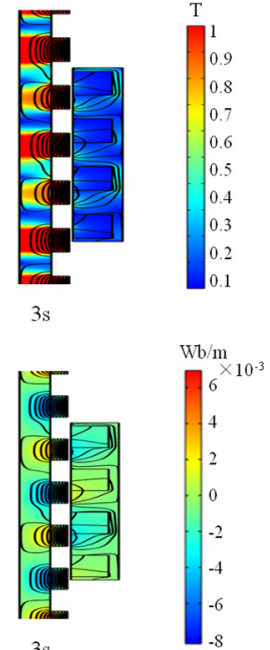

(b) The magnetic vector potential

Figure 8. (a) The modulus of density; (b) The magnetic vector potential.

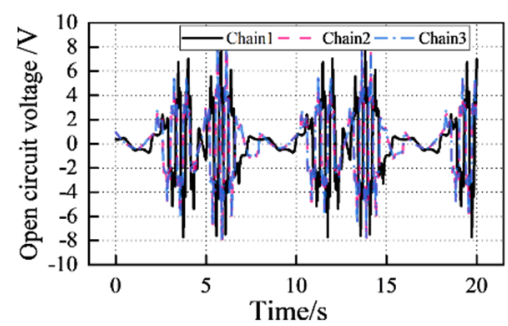

Figure 9. The waveform of induced voltage.

\section{Experimental Analysis}

\subsection{Experimental Prototype}

To verify the power generation performance of the wave power conversion device, a prototype was made according to the above mathematical model calculation and simulation results. In this design, the core generation element of each elastic linear generation branch 
chain is a cylindrical linear generator, which has two degrees of freedom of translation and rotation around its axis. The two parallel optical axes shown in Figure 10a are used in conjunction with the linear bearing shown in Figure 10b. The positions of the two optical axes correspond to the linear moving bearing of the stator part. The optical axes are fixed by the motion cage to limit the rotational freedom of the linear generator and achieve the matching of the branch chain freedom in the 3-UPU parallel mechanism. Meanwhile, four symmetrical linear moving bearings ensure the stability of the air gap between the stator and the stator. As shown in Figure 10c, the stator yoke is connected to a sealed space and fixed to the platform by a universal joint. The motion cage at the lower end of the actuator can be connected with the motion float through a universal joint. The copper wires in the stator yoke are externally wrapped with insulation material and wound into multiturn coils in a circular manner to avoid short-circuit connection between each turn of wires and to improve the induced electromotive force by connecting coils in parallel.

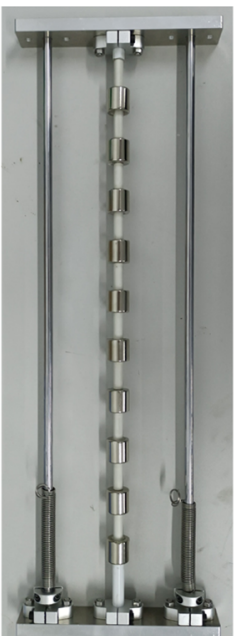

(a)

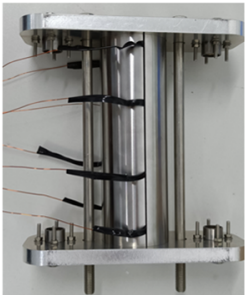

(b)

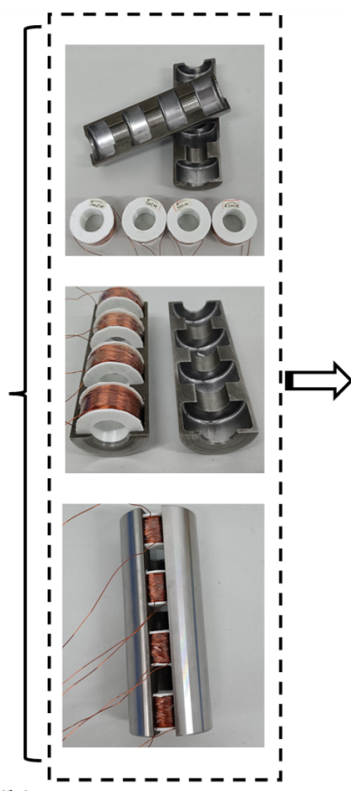

b)

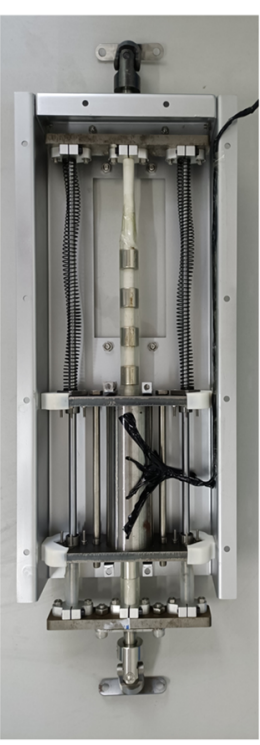

(c)

Figure 10. Design of flat-acting cylindrical linear generator (a) optical axis translation structure; (b) stator of the linear generator; (c) Single degree of freedom cylindrical linear generator.

Figure 11 shows the physical structure of the parallel direct-drive linear generator. The device has the following functions:

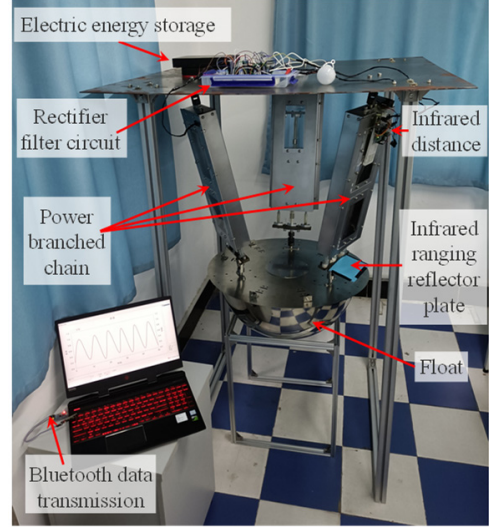

(a)

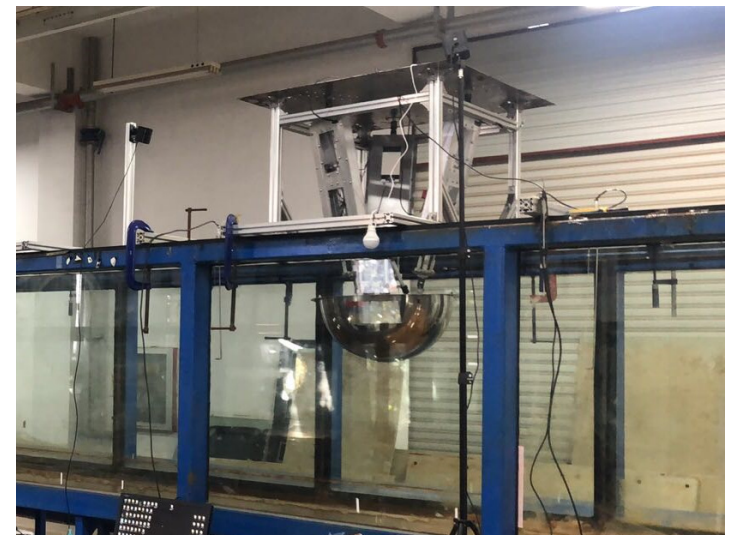

(b)

Figure 11. (a) The physical structure of the wave-energy converter; (b) Experimental layout. 
(1) Limiting the DOF of rotation to ensure three-dimensional pure horizontal motion and to capture multidirection wave energy;

(2) The GY-53 infrared ranging sensor, Bluetooth wireless transmission module and Arduino control board are used to form a linear ranging device, which realizes the real-time monitoring the relative displacement between mover and stator in linear generators.

(3) Using the rectification filter module and energy memory to store the electric energy generated by the three power generation branch chains.

Figure 12 presents the schematic diagram of the external rectifier filter circuit of the wave-energy conversion device with three elastic power generation branch chains, which convert irregular voltage waveform into DC and store it. Figure 13 shows the circuit management diagram of the proposed wave-energy converter where $L_{\text {Winding }}$ is the equivalent series inductance of the winding, $R_{\text {load }}$ is the load resistance, $C_{\mathrm{f}}$ is the filtering capacitance. Each linear generator is rectified and connected in parallel to the filter circuit to provide power for the load.
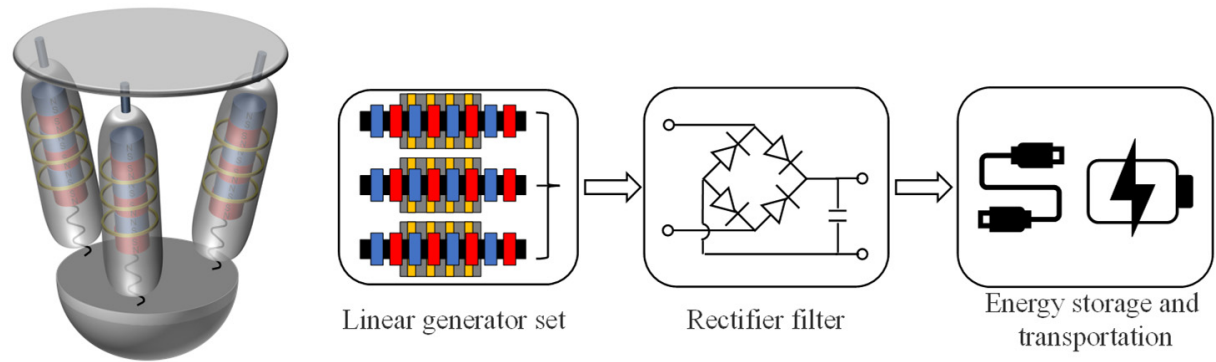

Figure 12. The schematic diagram of the external rectifier filter circuit.

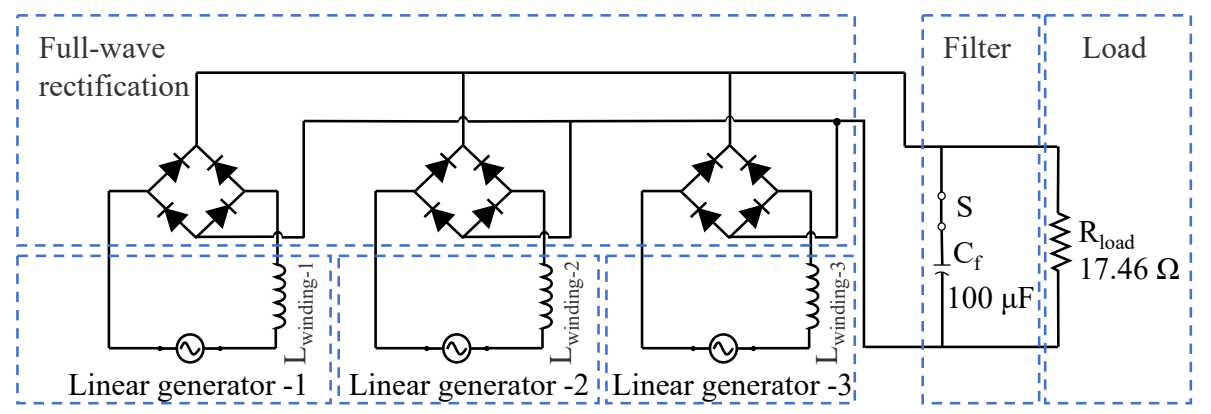

Figure 13. Equivalent circuit diagram of the WEC with load.

\subsection{Experimental Results}

To test the actual power generation efficiency of the multi-DOF device, a wave tank experiment was conducted in the in the Ocean University of China, Qingdao City, Shandong Province, China. The size of the wave tank is $25 \mathrm{~m}$ in length, $1.5 \mathrm{~m}$ in width and $1.2 \mathrm{~m}$ in height, and the experiments were carried out under regular wave conditions. The prototype was placed in the tank, and the wave height and wave period of the tank were set to $0.1 \mathrm{~m}$ and 2-4 s, respectively. A voltage limiter is connected to the circuit to ensure that the voltage across the bulb does not exceed the rated voltage value of $14 \mathrm{~V}$, and a TektronixDPO3014 ${ }^{\circledR}$ oscilloscope is used to record the voltage across the load of the experimental prototype as shown in Figure 14. When the wave period in the wave tank is $3 \mathrm{~s}$, the WEC can reach the rated voltage value of the load in a shorter time, which means that the device can achieve higher wave-energy conversion efficiency under this wave parameter. 


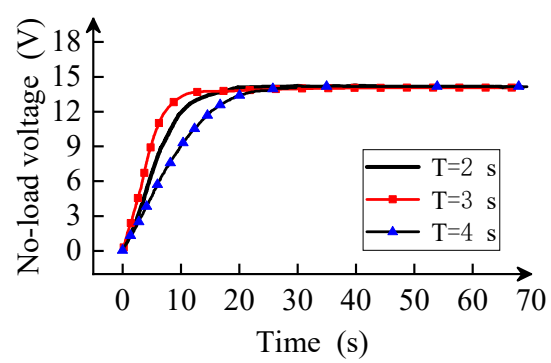

Figure 14. No-load voltage diagram under different wave periods.

Considering the real-time motion state and wave-energy conversion efficiency of the GY-53 infrared ranging sensor measuring device, a high-speed camera is used to record the motion of the WEC at the same time interval within a period, as shown in Figure 15a-f. It can be observed that the WEC remains stable during the entire operation process, the moving float realizes the spatial translational motion, in Figure 15c, the wave reaches the crest, and the float is at the highest point of motion; in Figure 15f, the wave reaches the trough, and the float then drops to the lowest point. Each power generation branch chain continues to generate electricity under the wave excitation.
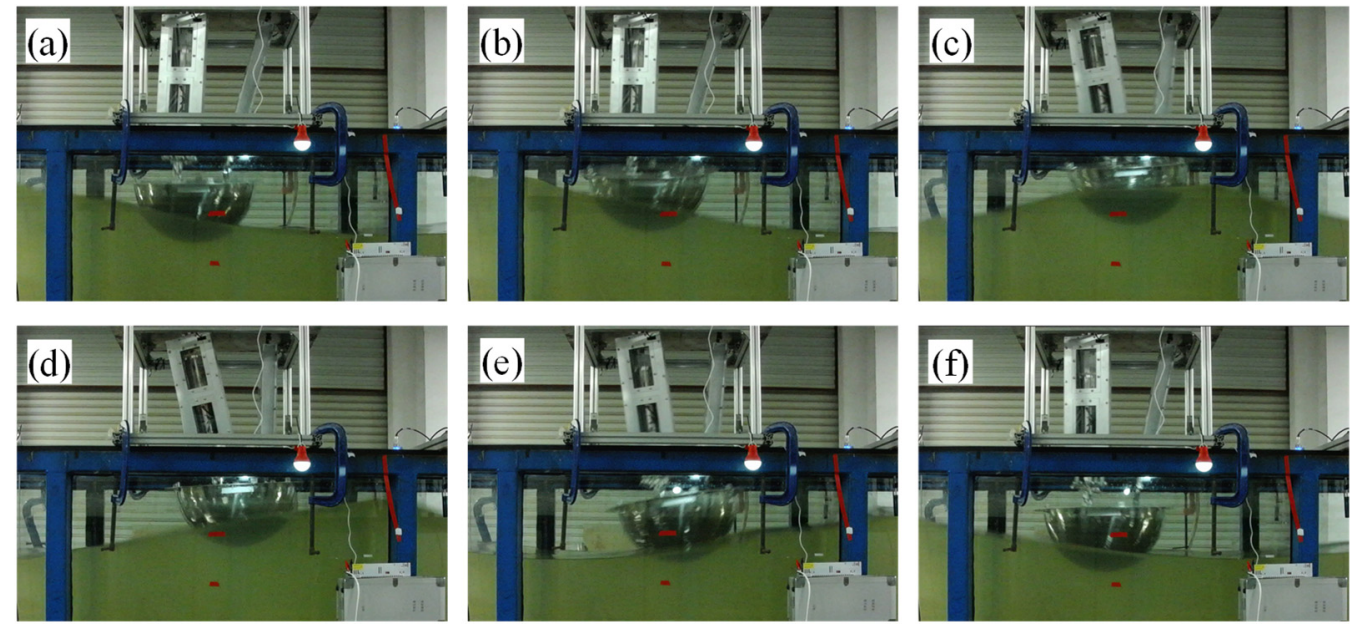

Figure 15. The wave tank test under $\Delta=0.4, \mathrm{H}=0.1 \mathrm{~m}, \mathrm{~T}=3 \mathrm{~s}$. (a) $0.5 \mathrm{~s}$; (b) $1 \mathrm{~s} \mathrm{(c)} 1.5 \mathrm{~s}$; (d) $2 \mathrm{~s}$; (e) $2.5 \mathrm{~s} ;(\mathbf{f}) 3 \mathrm{~s}$.

As shown in Figure 16a,b, when the device reaches a stable motion state, the experimental results are compared with the calculation results of the mathematical model, and the comparison result indicates that the proposed mathematical model can well predict the real-time motion trend of the device. However, it should be noted that the stability of wave height has a great influence on the experimental results. According to Figure 17, when the peaks of two adjacent waves are inconsistent, the trajectory of the moving float will change, and the length variation of each power generation branch chain will also be affected, leading to deviation between the theoretical predicted value and the experimental results. This also confirms the importance of real ocean environment studies to build wave-energy converter models. 


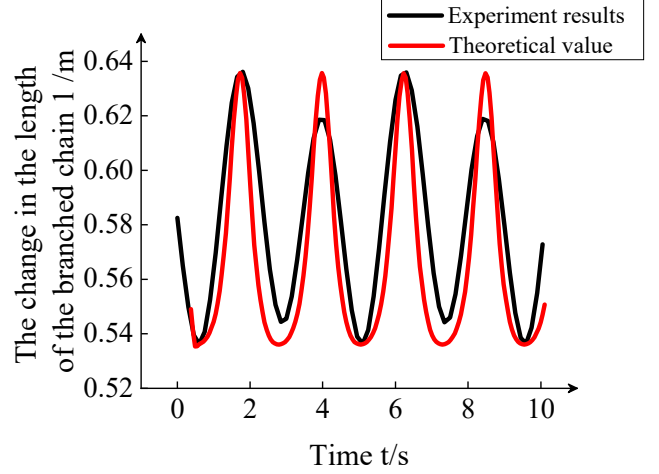

(a)

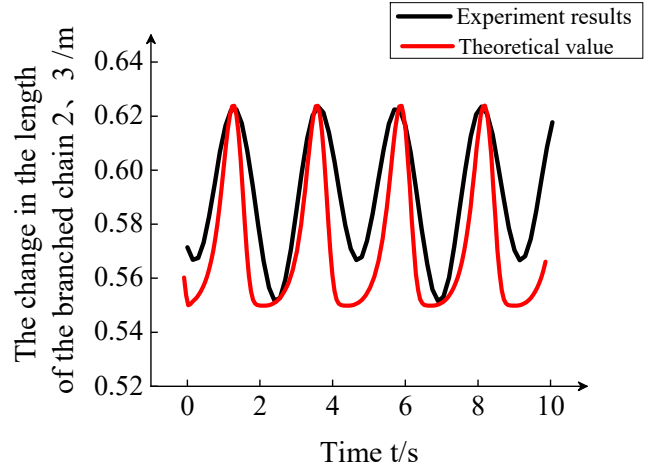

(b)

Figure 16. Comparison between theoretical analysis and experimental results (a) The change in the length of branched chain 1; (b) The change in the length of branched chain 2, 3 .

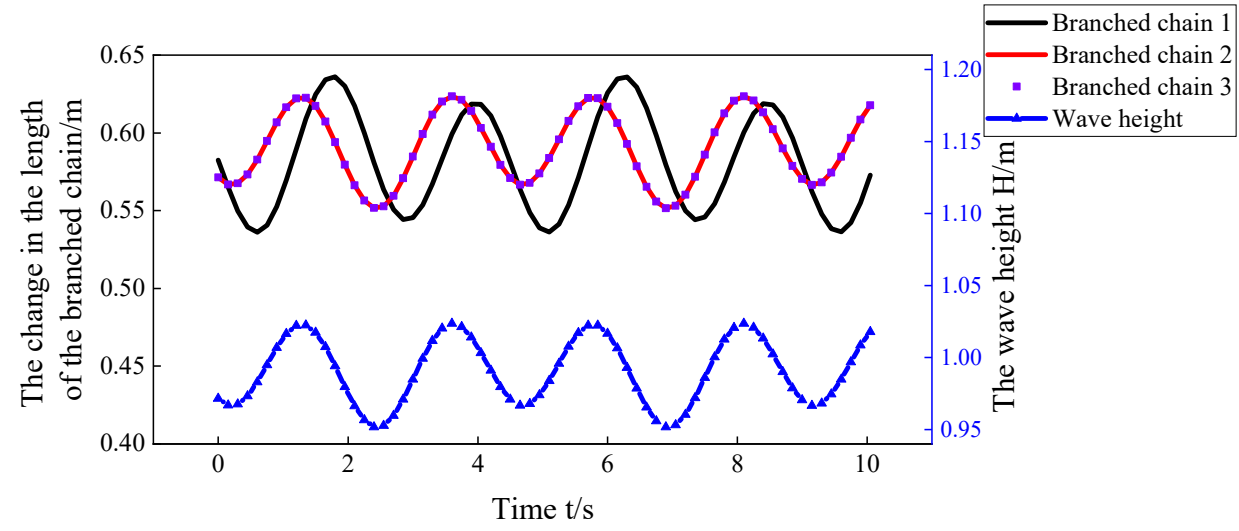

Figure 17. The variation in branch chain length and wave height.

\section{Conclusions}

This paper proposes a multi-DOF WEC based on a parallel mechanism. The dynamics model of the device was built up in terms of the wave mechanics, and an experimental prototype was manufactured and installed to verify the numerical analysis results. The proposed small-scale WEC can match the low-frequency wave motion by adjusting the size of the fixed platform and the moving float. The influence on the wave-energy conversion efficiency of the structure geometry size was investigated. The results show that waveenergy conversion efficiency of the multi-DOF conversion system is at most $39.91 \%$ higher than that of a single-DOF system, and the increase in the structure geometry size can improve the wave-energy conversion efficiency of the device for low-frequency waves. The cost of the WEC is mainly concentrated on the permanent magnet material, the external steel frame and the supporting measurement system. This research uses the high reliability of the parallel mechanism and the multi-DOF motion to realize the efficient power generation of the small-sized prototype, reducing the experimental prototype cost, which also means lower installation, maintenance and recycling costs of the device, contributing to higher economic efficiency. The wave simulation through the wave tank can more conveniently control the wave parameters, facilitate the comparison and analysis with the theoretical calculation, and reduce the influence of uncontrollable factors such as temperature, wind speed and ocean current. This research process is more convenient for experimental analysis and device optimization.

The rationality of the proposed device is verified through the mathematical model and experimental analysis, which provides a reference for practical engineering applications. However, there are still some aspects that need to be further improved: 
1. In real applications, the electromagnetic damping coefficient is not a constant, which is related to the structure of the generator and the relative running speed of the stator. The approximation of the electromagnetic damping coefficient to a constant can reduce the difficulty of the dynamic analysis of the mechanism and more intuitively analyze the influence of the structure.

2. In future work, the efficiency of small point absorption WEC will be improved through additional motion control strategies and structural optimization of the linear generator.

Author Contributions: Conceptualization, T.Y.; methodology, T.Y.; software, Y.W.; validation, T.Y. and Z.W.; formal analysis, T.Y.; investigation, T.Y.; resources, T.L.; data curation, Y.W.; writingoriginal draft preparation, Y.W.; writing—review and editing, T.Y.; visualization, T.Y.; supervision, Z.W. and Z.T.; project administration, T.Y.; funding acquisition, T.Y. All authors have read and agreed to the published version of the manuscript.

Funding: This research was funded by the National Natural Science Foundation of China, grant number 51775166.

Acknowledgments: The authors would like to thank the Hebei University of Technology and Ocean University of China.

Conflicts of Interest: The authors declare no conflict of interest.

\section{References}

1. Falcão, A.F.d.O. Wave energy utilization: A review of the technologies. Renew. Sustain. Energy Rev. 2010, 14, 899-918. [CrossRef]

2. Falcão, A.F.d.O.; Henriques, J.C.C. Oscillating-water-column wave energy converters and air turbines: A review. Renew. Energy 2016, 85, 1391-1424. [CrossRef]

3. Al Shami, E.; Zhang, R.; Wang, X. Point Absorber Wave Energy Harvesters: A Review of Recent Developments. Energies 2019, 12, 47. [CrossRef]

4. Salter, S.H.; Taylor, J.R.M.; Caldwell, N.J. Power conversion mechanisms for wave energy. Proc. Inst. Mech. Eng. Part M J. Eng. Marit. Environ. 2002, 216, 1-27. [CrossRef]

5. Waters, R.; Stålberg, M.; Danielsson, O.; Svensson, O.; Gustafsson, S.; Strömstedt, E.; Eriksson, M.; Sundberg, J.; Leijon, M. Experimental results from sea trials of an offshore wave energy system. Appl. Phys. Lett. 2007, 90, 034105. [CrossRef]

6. Son, D.; Belissen, V.; Yeung, R.W. Performance validation and optimization of a dual coaxial-cylinder ocean-wave energy extractor. Renew. Energy 2016, 92, 192-201. [CrossRef]

7. Qiu, S.; Wang, H. A Novel Segmented Structure and Control Method for a Permanent-Magnet Linear Generator to Broaden the Range of Efficient Energy Capture. J. Mar. Sci. Eng. 2019, 7, 101. [CrossRef]

8. Molla, S.; Farrok, O.; Rahman, A.; Bashir, S.; Islam, R.; Kouzani, A.Z.; Mahmud, M.A.P. Increase in Volumetric Electrical Power Density of a Linear Generator by Winding Optimization for Wave Energy Extraction. IEEE Access 2020, 8, 181605-181618. [CrossRef]

9. Siegel, S.G. Numerical benchmarking study of a Cycloidal Wave Energy Converter. Renew. Energy 2019, 134, 390-405. [CrossRef]

10. Farrok, O.; Islam, R.; Muttaqi, K.M.; Sutanto, D.; Zhu, J. Design and Optimization of a Novel Dual-Port Linear Generator for Oceanic Wave Energy Conversion. IEEE Trans. Ind. Electron. 2020, 67, 3409-3418. [CrossRef]

11. Aderinto, T.; Li, H. Conceptual Design and Simulation of a Self-Adjustable Heaving Point Absorber Based Wave Energy Converter. Energies 2020, 13, 1997. [CrossRef]

12. Cargo, C.; Hillis, A.; Plummer, A. Strategies for active tuning of Wave Energy Converter hydraulic power take-off mechanisms. Renew. Energy 2016, 94, 32-47. [CrossRef]

13. Oh, Y.J.; Park, J.S.; Hyon, B.J.; Lee, J. Novel Control Strategy of Wave Energy Converter Using Linear Permanent Magnet Synchronous Generator. IEEE Trans. Appl. Supercond. 2018, 28, 5204705. [CrossRef]

14. Younesian, D.; Alam, M.-R. Multi-stable mechanisms for high-efficiency and broadband ocean wave energy harvesting. Appl. Energy 2017, 197, 292-302. [CrossRef]

15. Zheng, Z.; Yao, Z.; Chang, Z.; Yao, T.; Liu, B. A point absorber wave energy converter with nonlinear hardening spring power-take-off systems in regular waves. Proc. Inst. Mech. Eng. Part M J. Eng. Marit. Environ. 2020, 234, 820-829. [CrossRef]

16. Zhang, X.; Yang, J.; Xiao, L. Numerical study of an oscillating wave energy converter with nonlinear snap-through power-take-off systems in regular waves. In Proceedings of the International Ocean and Polar Engineering Conference, Busan, Korea, 15-20 June 2014.

17. Tarrant, K.; Meskell, C. Investigation on parametrically excited motions of point absorbers in regular waves. Ocean Eng. 2016, 111, 67-81. [CrossRef]

18. Chen, W.; Gao, F.; Meng, X. Kinematics and dynamics of a novel 3-degree-of-freedom wave energy converter. Proc. Inst. Mech. Eng. Part M J. Eng. Marit. Environ. 2018, 233, 687-698. [CrossRef] 
19. Huang, Z.; Zeng, D. Principle and Method of Calculating Freedom of Mechanism; Higher Education Press: Beijing, China, 2016; pp. 26-34.

20. Cummins, W.E. The Impulse Response Function and Ship Motions. Schiffstechnik 1962, 9, 101-109.

21. Ogilvie, T.F. Recent progress towards the understanding and prediction of ship motions. In Proceedings of the Sixth Symposium on Naval Hydrodynamics, Washington, DC, USA, 27-28 February 1964.

22. Wang, S.; Liang, B. Ocean Engineering Wave Mechanics; Ocean University of China Press: Qingdao, China, 2013 ; pp. 68-75.

23. Liang, C.; Ai, J.; Zuo, L. Design, fabrication, simulation and testing of an ocean wave energy converter with mechanical motion rectifier. Ocean Eng. 2017, 136, 190-200. [CrossRef]

24. Do, H.-T.; Dang, T.-D.; Ahn, K.K. A multi-point-absorber wave-energy converter for the stabilization of output power. Ocean Eng. 2018, 161, 337-349. [CrossRef]

25. Lejerskog, E.; Boström, C.; Hai, L.; Waters, R.; Leijon, M. Experimental results on power absorption from a wave energy converter at the Lysekil wave energy research site. Renew. Energy 2015, 77, 9-14. [CrossRef]

26. Curto, D.; Viola, A.; Franzitta, V.; Trapanese, M.; Cardona, F. A New Solution for Sea Wave Energy Harvesting, the Proposal of an Ironless Linear Generator. J. Mar. Sci. Eng. 2020, 8, 93. [CrossRef] 